\title{
Determination of the Thermal Conductivity by Using the Hot Wire Method: Theory, Simulation and Experiment
}

\author{
Giovanni Alcocer \\ Independent Researcher, Guayaquil, Ecuador.Email: giov_alc_science@hotmail.com \\ Master in Physics with Specialization in Astrophysics and Medical Physics, Professor of Physics, Advanced Mathematics and Science in General.
}

DOI: 10.46382/MJBAS.2020.4309

The measurement of the physical properties (density, viscosity, surface tension, thermal conductivity, etc) is of great importance to the research industry and for the physical, chemical and biomedical applications.

The thermal conductivity is a measurement of the material's ability to conduct heat. The transient hot wire method is a suitable method to measure the thermal conductivity due to its very cheap cost of construction, accuracy and because it is a fast method of measurement.

The implementation requires accurate temperature sensing, automatic control, data acquisition and data analysis. The basic procedure consists of measuring the temporal temperature rise in a thermoresistance (thin wire) immersed in the solution by applying an electrical current in the wire.

Therefore, the wire works as a heat source and a temperature sensor. The time of measurement is very short and therefore the convection effect could be minimized. Then, the heat transfer to the infinite medium is due only to the conduction transfer effect.

The thermal conductivity can be determined from the slope of the curve $\Delta T$ versus $\ln (t)$ due to the linear relation between $\Delta T$ and $\ln (t)$.

Keywords: Thermal Conductivity, Hot Wire Method, Physical Properties, Theory, Simulation, Experiment

\section{Introduction}

The measurement of the physical properties (density, viscosity, surface tension, thermal conductivity, etc.) is of great importance to the research, industry and physical, chemical and biomedical applications. The thermal conductivity is a measurement of the material's ability to conduct heat. The Transient Hot Wire method is a suitable method to measure the thermal conductivity due to its very cheap cost of construction, accuracy and because it is a fast method of measurement. The implementation requires accurate temperature sensing, automatic control, data acquisition and data analysis.

The basic procedure consists of measuring the temporal temperature rise in a thermoresistance (thin wire) immersed in the solution by applying an electrical current in the wire. Therefore, the wire works as a heat source and a temperature sensor. It is necessary to coat the platinum wire in order to avoid disturbances and perturbations of the signals. Besides, the convection heat transfer effects can be minimized due to the brief period of time of the measurement. For other hand, if a small convection effect appears, it can be identified and corrected by using the deviation of the linearity in the plot of $\Delta \mathrm{T}$ versus $\ln (\mathrm{t})$. Then we can adjust the time control of the measurement to minimize it. If the physical properties are assumed to be constants (which is true in this case due to the short period time of measurement), the thermal conductivity can be determined from the slope of the curve $\Delta \mathrm{T}$ versus $\ln (\mathrm{t})$. It is because of the linear relation between $\Delta \mathrm{T}$ and $\ln (\mathrm{t})$. A basic scheme of the experiment is showed in the figure 1.

It mainly consists of a testing container where is the liquid, the heat source/sensor of platinum wire and the coating of the cell (recipient is thermal isolated). Besides, we can observe the data acquisition system HP 34970 A connected to the PC computer by the serial RS232, the DC power supply and the Wheatstone bridge. We can 
observe three thermocouples in order to monitor the uniformity of the fluid. The computer controls the time, the signal measurements and also performs the processing data. By using the Lab-View software, it is possible to convert the voltage registered into temperature and finally it is converted to thermal conductivity.

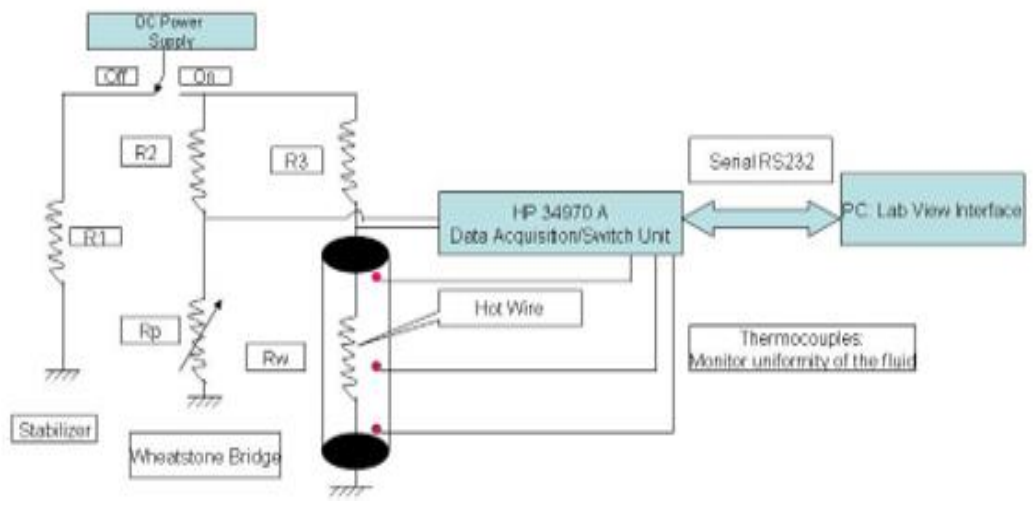

Fig.1 Basic Scheme of the Thermal Conductivity Measurement

The method consists of measuring the temporal temperature rise in a thin wire immersed in the liquid (which is initially at equilibrium) by applying an electrical current to the wire. Therefore, the wire is a heat source which produces a time-dependent temperature field within the liquid and also it acts as a sensor. As we mentioned before, the time of measurement is very short and therefore the convection effect could be minimized. Then, the heat transfer to the infinite medium is due only to the conduction transfer effect.

The theoretical model is derived from the analytical solution of the heat conduction equation. The supposition consists of considering an ideal condition of line heat source of radius $r \rightarrow 0$ and length $L \rightarrow \infty$. The principle of the hot-wire method is based on a constant ideal heat generation source with an infinitely long, thin continuous line-wire in an infinite/incompressible medium. Another assumption is that the line heat-source has uniform instant temperature everywhere. It is possible to get with a wire of small diameter, long length and/or small heat capacity located in a finite medium. Thus, the ideal case is approximated with a finite long wire embedded in a finite medium.

The equation for this temperature rise is derived from the Fourier's equation for 1-D transient heat conduction (with truncated higher-order terms):

$T(r, t)=\frac{Q \ln \left(\frac{4 a t}{r^{2} C}\right)}{4 \pi k}$

Where, $\mathrm{T}$ is the suitable temperature rise of the wire, $\mathrm{Q}$ is the heat dissipation per unit length, a is the thermal diffusivity of the test fluid and $\mathrm{C}$ is the exponent of Euler's constant: $C=e^{\gamma}$ where $\gamma=0.577$. The thermal diffusivity a is given by the formula $a=\frac{k}{\rho C_{p}}$ where $\mathrm{k}$ is the thermal conductivity of the fluid, $\rho$ is the density of the fluid and $c_{p}$ is the heat capacity of the fluid.

If we consider constant fluid medium properties and a fixed and arbitrary radius $r$ and after to do the subtraction for two times of (1) we obtain the following relation: 
$k=\frac{Q \ln \left(\frac{t_{2}}{t_{1}}\right)}{4 \pi\left(T_{2}-T_{1}\right)}$

From the equation $T(r, t)=\frac{Q \ln \left(\frac{4 a t}{r^{2} C}\right)}{4 \pi k}$, the slope of the curve $T$ vs $\ln (\mathrm{t})$ in a logarithmic scale of time is: $m=\frac{Q}{4 \pi k}$. Finally, the thermal conductivity is equal to: $k=\frac{\mathrm{Q}}{4 \pi \mathrm{m}}$

Afterward, we obtain the value of the thermal conductivity by mean of continuous processing measurement data. Therefore, we must have many points in the curve $\Delta \mathrm{T}$ versus $\ln (\mathrm{t})$ in order to have good statistical analysis. The thermal diffusivity can be found from the intercept of the linear function $T(r, t)=\frac{Q \ln \left(\frac{4 a t}{r^{2} C}\right)}{4 \pi k}$ :

$T=\frac{Q}{4 \pi k}\left[\ln (t)+\ln \left(\frac{4 a}{r^{2} C}\right)\right]$

Nevertheless, we should consider that there are some deviations from the ideal model due to the effects of the finite length of the wire and the finite/compressible medium. Also, the heat losses or heat gains from the wire cause deviations of the ideal uniform temperature profile around of the wire. It occurs at small times and so the heat transferred by conduction can be approximately linear in time as long as the heat dissipated by the wire can be confined to the liquid (so, we must take $t>t_{\min }$ ). Furthermore, for longer times the temperature profile is not more linear due to convective heat transport (with the possibility of mass transfer too) and besides the boundary effects take place (longitudinal heat gains or longitudinal heat losses due to the finite length of the wire which produces deviations on the uniform temperature profile around the wire) (thus, we must take $t<t_{\max }$ ). The solution to those problems consists of considering a time window, which is open for measurement between $t_{\min }$ and $t_{\max }$.

In practice, the change in the resistance of the sensor/wire (voltage change of the wire) as function of the time is used as a measure of the temperature change in the time and therefore a way to measure the searched parameter after of a calibration procedure. Typically, it is used a Wheatstone bridge circuit to measure the resistance change. The reference temperature of the fluid is measured by the next formula:

$T=T_{o}+\frac{\left[\Delta T\left(t_{1}\right)+\Delta T\left(t_{2}\right)\right]}{2}$

Where, To is the initial temperature of the fluid and $\Delta \mathrm{T}\left(\mathrm{t}_{1}\right), \Delta \mathrm{T}\left(\mathrm{t}_{2}\right)$ are the temperature increases at times $\mathrm{t}_{1}$ and $\mathrm{t}_{2}$ respectively. The next table shows the measurement of the thermal conductivity with the uncertainties and repeatability for those liquids [1].

\begin{tabular}{|c|c|c|c|c|c|}
\hline Fluid & $\begin{array}{c}\text { Reference } \\
{\left[\mathrm{W} / \mathrm{m}^{\circ} \mathrm{C}\right]}\end{array}$ & $\begin{array}{c}\text { Measured } \\
{\left[\mathrm{W} / \mathrm{m}^{\circ} \mathrm{C}\right]}\end{array}$ & $\begin{array}{c}\text { Bias } \\
\text { Error }\end{array}$ & $\begin{array}{c}\text { Precision } \\
\text { Error } \\
(95 \%)\end{array}$ & $\begin{array}{c}\text { Uncertainty in } \\
\text { Repeatability }\end{array}$ \\
\hline $\begin{array}{c}\text { Ethylene } \\
\text { Glycol } \\
\left(32.5^{\circ} \mathrm{C}\right)\end{array}$ & 0.254 & 0.253 & $\begin{array}{c}-0.395 \\
\%\end{array}$ & $2.03 \%$ & $2.06 \%$ \\
\hline $\begin{array}{c}\text { Distilled } \\
\text { water } \\
\left(\sim 26^{\circ} \mathrm{C}\right)\end{array}$ & 0.612 & 0.619 & $1.2 \%$ & $2.23 \%$ & $2.52 \%$ \\
\hline
\end{tabular}

Table 1: Values of the thermal conductivity for Ethylene Glycol and Distilled water with the respective uncertainties [1] 
We can see that the bias error is within $1.5 \%$ and the precision error and the repeatability error within $2.5 \%$ with a $95 \%$ of confidence probability.

\section{Design of the Hot Wire Apparatus}

The main components of the cell will be: a recipient made of Platinum and the heating/sensing device made of Platinum - Rhodium $10 \%$ wire. The important properties to consider for the material of the wire are: good reproducibility of its electrical properties, highly resistant to corrosion and that the properties of the metal don't change during the work operation. The main parameters of the design are:

Material, radius and length of the hot-wire

Radius of the test sample (crucible)

Length of the test sample (crucible)

The dimensions of the $\mathrm{Pt}-\mathrm{Rh} 10 \%$ are:

$\mathrm{L}_{\mathrm{w}}=44.3 \mathrm{~cm}$ (length of the wire)

$\mathrm{r}_{\mathrm{w}}=125 \mu \mathrm{m}$ (radius of the wire)

The resistance of the wire at room temperature $\left(20^{\circ} \mathrm{C}\right)$ is: $\mathrm{R}_{\mathrm{w}}=2 \Omega$

The electrical resistivity $\rho$ is given by:

$\rho=R_{w} \frac{A}{L_{w}}$

Where:

$\rho:$ the resistivity of the wire (measured in $\mu \Omega$-cm)

$\mathrm{R}_{\mathrm{w}}$ : the electrical resistance of the wire $(\mu \Omega)$

$\mathrm{L}_{\mathrm{w}}$ : the length of the wire $(\mathrm{cm})$

A: the cross sectional area of the wire $\left(\mathrm{cm}^{2}\right)$

where $\mathrm{A}=\pi \mathrm{r}^{2}$.

Therefore, by replacing the values of the length, resistance and the radius, the resistivity is equal to: $\rho=22.16$ $\mu \Omega$-cm.

The crucible has the next dimensions:

$\mathrm{V}_{\text {cell }}=125 \mathrm{~cm}^{3}$

$\mathrm{L}_{\text {cell }}=5 \mathrm{~cm}$

$\mathrm{r}_{\mathrm{cell}} \approx 2.89 \mathrm{~cm}$

The resistivity as function of the temperature is given by: $\rho=\rho_{o}\left[1+a\left(T-T_{0}\right)+b\left(T-T_{o}\right)^{2}\right]$ 
Where, $\rho_{\mathrm{o}}$ is the resistivity at the temperature $\mathrm{T}_{\mathrm{o}}\left({ }^{\circ} \mathrm{C}\right)$, a and $\mathrm{b}$ are the temperature coefficients of the resistivity and $\rho$ is the resistivity at the temperature $\mathrm{T}$. If we divide both sides of the last equation by $\mathrm{A} / \mathrm{L}_{\mathrm{w}},=R_{w} \frac{A}{L_{w}}$, we obtain: $\mathrm{R}=\mathrm{R}_{\mathrm{o}}\left[1+\mathrm{a}\left(\mathrm{T}-\mathrm{T}_{\mathrm{o}}\right)+\mathrm{b}\left(\mathrm{T}-\mathrm{T}_{\mathrm{o}}\right)^{2}\right]$

It is the famous Callendar equation. For the Pt-Rh $10 \%$ and from 0 to $850{ }^{\circ} \mathrm{C}$, we have:

$\mathrm{R}_{\mathrm{o}}=2 \Omega\left(20{ }^{\circ} \mathrm{C}\right), \rho_{\mathrm{o}}=22.16 \mu \Omega-\mathrm{cm}$

$\mathrm{a}=1,63 * 10^{-3}\left({ }^{\circ} \mathrm{C}^{-1}\right)\left(\right.$ valid for temperature change: 0 to $100{ }^{\circ} \mathrm{C}$ )

$\mathrm{T}_{0}=20^{\circ} \mathrm{C}$

Therefore, we need to determine $\mathrm{b}$ experimentally at another temperature point. But it is possible to obtain the calibration equation by a practical way. We can use the design of the Wheatstone bridge in order to obtain $\mathrm{R}_{\mathrm{o}}$ from the other resistances of the bridge at the work temperature. Besides, it is necessary to use only a polynomial of first order because the temperature change $\left(\mathrm{T}-\mathrm{T}_{\mathrm{o}}\right)$ is small $\left(\left(\mathrm{T}-\mathrm{T}_{\mathrm{o}}\right)^{2}\right.$ is very small). Thus, we can use only the constant a, valid in this range of the temperature change (it is less than $10^{\circ} \mathrm{C}$ ). So, our calibration equations are:

$\rho=\rho_{\mathrm{o}}\left[1+\mathrm{a}\left(\mathrm{T}-\mathrm{T}_{\mathrm{o}}\right)\right]$

$\mathrm{R}=\mathrm{R}_{\mathrm{o}}\left[1+\mathrm{a}\left(\mathrm{T}-\mathrm{T}_{\mathrm{o}}\right)\right]$

Where, $\mathrm{R}_{\mathrm{o}}$ is calculated from the Wheatstone bridge and $\mathrm{a}=1,63 * 10^{-3}\left({ }^{\circ} \mathrm{C}^{-1}\right)$, the temperature coefficient of electrical resistivity [2]. In order to do the analysis, we do a scheme of our Wheatstone bridge:

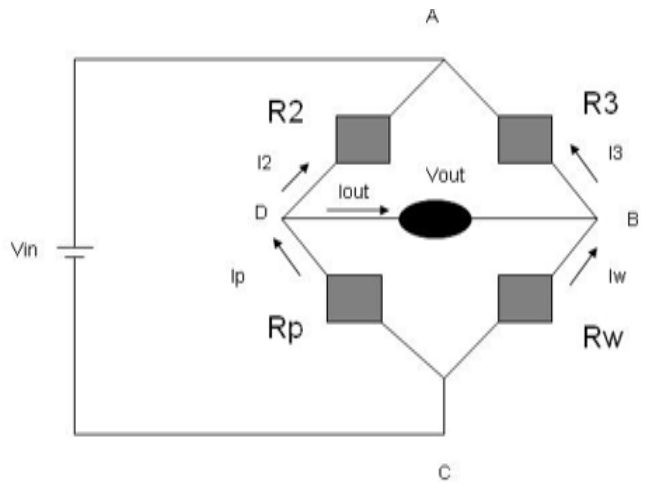

Fig.2 Scheme of the Wheatstone Bridge

Where:

$\mathrm{R}_{\mathrm{w}}$ : resistance of the wire to be measured

$\mathrm{R}_{2}, \mathrm{R}_{3}$ : resistors of known values

$\mathrm{R}_{\mathrm{p}}$ : potentiometer adjustable to the specific value which is required in the experiment.

At the beginning, the bridge is balanced until the voltage output Vout is approximately zero (few $\mu \mathrm{V}$ ). Therefore, no current flow through the points $B$ and $D$ (galvanometer). Namely, we can adjust $R_{p}$ until we get this condition. 
From the Kirchoff's rule of the currents and voltages, we have:

$\mathrm{I}_{3}=\mathrm{I}_{\text {out }}+\mathrm{I}_{\mathrm{w}}$

$\mathrm{I}_{2} \mathrm{R}_{2}-\mathrm{I}_{3} \mathrm{R}_{3}=\mathrm{I}_{\text {out }} \mathrm{R}_{\text {out }}$

$\mathrm{I}_{\mathrm{p}}=\mathrm{I}_{2}+\mathrm{I}_{\text {out }}$

$\mathrm{I}_{\text {out }} R_{\text {out }}=I_{\mathrm{w}} R_{\mathrm{w}}-\mathrm{I}_{\mathrm{p}} R_{\mathrm{p}}$

$\mathrm{I}_{3} \mathrm{R}_{3}=\mathrm{I}_{2} \mathrm{R}_{2}\left(\mathrm{I}_{\text {out }}=0\right)$

$\mathrm{I}_{\mathrm{w}} \mathrm{R}_{\mathrm{w}}=\mathrm{I}_{\mathrm{p}} \mathrm{R}_{\mathrm{p}}\left(\mathrm{I}_{\mathrm{out}}=0\right)$

Dividing the last two equations member to member, we obtain:

$\frac{I_{3} R_{3}}{I_{w} R_{W}}=\frac{I_{2} R_{2}}{I_{p} R_{p}}$

But $\mathrm{I}_{3}=\mathrm{I}_{\mathrm{w}}$ and $\mathrm{I}_{\mathrm{p}}=\mathrm{I}_{2}$ (because $\mathrm{I}_{\text {out }}=0$ ), therefore, we have:

$\frac{R_{3}}{R_{w}}=\frac{R_{2}}{R_{p}}$

$R_{w}=\frac{R_{3} R_{p}}{R_{2}}$

Therefore, we can set:

$\mathrm{R}_{3}=\mathrm{R}_{2}$ (for example, $1 \mathrm{k} \Omega$ )

$\mathrm{R}_{\mathrm{p}}$ : a potentiometer of $100 \Omega$.

Besides, it is necessary a resistance $R_{1}$ of $1 \mathrm{k} \Omega$ (showed in the figure 1) used to stabilize the power supply. The potentiometer should be setted approximately to $2 \Omega$ (and so $\mathrm{R}_{\mathrm{w}}=2 \Omega$ too) at $20^{\circ} \mathrm{C}$, when the current has a value of $0 \mathrm{~A}$ through the points $\mathrm{B}$ and $\mathrm{D}$.

In other words, when the temperature is higher (for example: $1000^{\circ} \mathrm{C}$ ), we can set the potentiometer at an another value to get an output voltage $\left(\mathrm{V}_{\text {out }}\right)$ of approximately zero volts. We calculate $\mathrm{R}_{\mathrm{w}}$ from the value of the potentiometer $\mathrm{R}_{\mathrm{p}}$ and it is the value of $\mathrm{R}_{\mathrm{wo}}$ at $1000{ }^{\circ} \mathrm{C}\left(\mathrm{To}=1000{ }^{\circ} \mathrm{C}\right)$. For other temperatures, the resistance from the hot wire can be measure by using the formula:

$\mathrm{R}_{\mathrm{w}}=\mathrm{R}_{\mathrm{wo}}\left[1+\mathrm{a}\left(\mathrm{T}-\mathrm{T}_{\mathrm{o}}\right)\right]$

Thus, when there is a change of temperature in the liquid, there is a resistance change in the wire and it produces a $\mathrm{V}_{\text {out }}$ different to zero volts. We apply the voltage divisor in the node $\mathrm{B}$ and after we substrate it from the voltage divisor of the node $\mathrm{D}$.

It is as follows:

$V_{\text {out }}=\frac{R_{w o}+\Delta R_{w}}{R_{3}+R_{w o}+\Delta R_{w}} V_{\text {in }}-\frac{R_{p}}{R_{2}+R_{p}} V_{\text {in }}$ 
We solve for the variable $\Delta \mathrm{R}_{\mathrm{w}}$ :

$\Delta R w=\frac{R_{3}\left[\left(R_{2}+R_{p}\right) \frac{V_{\text {out }}}{V_{\text {in }}}+R_{p}\right]}{\left[R_{2}-\left(R_{2}+R_{p}\right) \frac{V_{\text {out }}}{V_{\text {in }}}\right]}-R w o$

The temperature change is as follows:

$\mathrm{R}_{\mathrm{w}}=\mathrm{R}_{\mathrm{wo}}\left[1+\mathrm{a}\left(\mathrm{T}-\mathrm{T}_{\mathrm{o}}\right)\right]$

$\Delta T=\frac{\Delta R_{w}}{a R_{w o}}$

The voltage drop of the wire (voltage divisor is:

$V_{w}=\frac{V_{i n} R_{w}}{R_{w}+R_{3}}$

The heat flux per unit of length is given by the next equation (because the electrical power is given by $P=I^{2} R=V^{2} / R$ and $\mathrm{WL}_{\mathrm{w}}=\mathrm{QL}_{\mathrm{w}}$ is the heat flux of the wire, electrical power):

$Q=\frac{V_{2}^{2}}{L_{w} R_{w}}$

Finally, the thermal conductivity is given by:

$k=\frac{Q \ln \left(\frac{t_{2}}{t_{1}}\right)}{4 \pi\left(T_{2}-T_{1}\right)}$

In order to complete the design, we consider a time window from 1 to $10 \mathrm{~s}$. As we said before, if a small convection effect appears, it can be identified and corrected by using the deviation of the linearity in the plot of $\Delta \mathrm{T}$ versus $\ln (\mathrm{t})$. Then, we can decrease the time window in order to consider only the linear part. Other approximated values of the experiment are:

- Input voltage range: $0-25 \mathrm{~V}$

- Range of the voltage output through the hot wire $\approx 0-1 \mathrm{~V}$

- Resistance increase of the wire $\approx 0-1 \Omega$

- Power to be dissipated by the wire $\approx 0-1 \mathrm{~W}$

- Current through the hot wire $\approx 0-1 \mathrm{~A}$

- Type of fluid medium: any chemical solution

- Full range of temperature: approximately up to $110{ }^{\circ} \mathrm{C}$

- Sensor will be not used under high pressure

3. Deduction of the equation for the temperature in a long thin wire carrying electric current embedded in a finite medium as an approximation to the infinite long, thin continuous line - wire heated along a line in an infinite/incompressible medium

The method of the transient hot wire technique is the most useful application of an instantaneous point source of heat given by a long thin wire carrying electric current [3]. The idea is very simple and powerful. The point source 
has the general solution $1 / \mathrm{r}$ of the potential theory, by the development of Green's functions in similar way to those problems of potential theory as in electrodynamics and quantum field theory for example.

Firstly, we are going to deduce the heat conduction equation. We imagine a differential control volume as it is showed in the figure 3 :
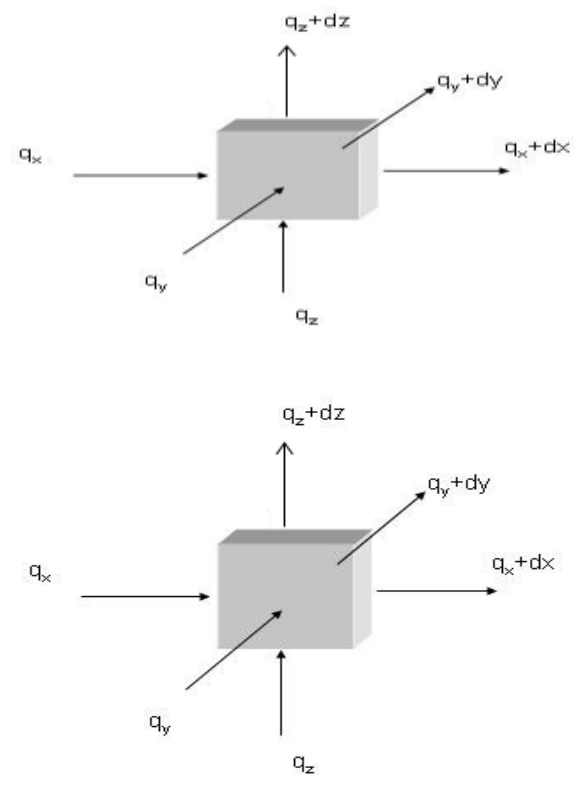

Fig.3 Differential Control Volume

In the figure showed, $\mathrm{q}_{\mathrm{x}}, \mathrm{q}_{\mathrm{y}}, \mathrm{q}_{\mathrm{z}}(\mathrm{W}: \mathrm{J} / \mathrm{s})$ are the heat transference velocity by the conduction in the $\mathrm{x}, \mathrm{y}$ and $\mathrm{z}$ coordinates. The heat transference velocity in the opposite surfaces are expressed by using Taylor series expansion. Therefore, we have:

$q_{x+d x}=q_{x}+\frac{\partial q_{x}}{\partial x} d x$

$q_{y+d y}=q_{y}+\frac{\partial q_{y}}{\partial y} d y$

$q_{z+d z}=q_{z}+\frac{\partial q_{z}}{\partial z} d z$

Also, we consider an internal thermal energy source, which is given by the expression:

$\frac{\partial E_{g}}{\partial t}=q^{\prime} d x d y d z$

Where, q' is the transferred energy velocity per volume of the medium $\left(\mathrm{W} / \mathrm{m}^{3}\right)$.

Besides, we must consider changes in the internal thermal energy stored by the control volume. It is given by the mathematical expression (without changes of phase):

$\rho c_{p} \frac{\partial T}{\partial t}$ : velocity of the internal energy change per volume $\left(\mathrm{c}_{\mathrm{p}}\right.$ is the specific heat of the medium at constant pressure: $\left.\mathrm{J} /\left(\mathrm{kg}-{ }^{\circ} \mathrm{K}\right)\right)$. 
$\frac{\partial E_{s}}{\partial t}=\rho c_{p} \frac{\partial T}{\partial t} d x d y d z$

Finally, we can present the general conservation energy:

$\frac{\partial E_{e}}{\partial t}-\frac{\partial E_{O}}{\partial t}+\frac{\partial E_{g}}{\partial t}=\frac{\partial E_{S}}{\partial t}$

Where, $E_{e}$ and $E_{o}$ are the entry energy and the output energy respectively.

The energy conservation is given by:

$q_{x}+q_{y}+q_{z}-q_{x+d x}-q_{y+d y}-q_{z+d z}+q^{\prime} d x d y d z=\rho c_{p} \frac{\partial T}{\partial t} d x d y d z$

$\mathrm{q}_{\mathrm{x}+\mathrm{dx}}, \mathrm{q}_{\mathrm{y}+\mathrm{dy}}, \mathrm{q}_{\mathrm{z}+\mathrm{dz}}$ were given before:

$-\frac{\partial q_{x}}{\partial x} d x-\frac{\partial q_{y}}{\partial y} d y-\frac{\partial q_{z}}{\partial z} d z+q^{\prime} d x d y d z=\rho c_{p} \frac{\partial T}{\partial t} d x d y d z$

For other hand, the heat conduction is given by the Fourier Law:

$\frac{\partial q}{\partial A}=-k \frac{\partial T}{\partial x}$

Where, $\mathrm{A}$ is the perpendicular area to the heat flux (heat transference velocity) and $\mathrm{k}$ is the thermal conductivity $\left[\mathrm{W} /\left(\mathrm{m}-{ }^{\circ} \mathrm{K}\right)\right]$, a characteristic property of the heat transference of the material. The minus sign is due to the reason that the heat propagation is in the direction of temperature decrease. By applying the Fourier law in each wall in our control volume, we obtain:

$q_{x}=-k d y d z \frac{\partial T}{\partial x}$

$q_{y}=-k d x d z \frac{\partial T}{\partial y}$

$q_{z}=-k d x d y \frac{\partial T}{\partial z}$

By the substitution of the last equations, we get the heat conduction equation:

$\frac{\partial\left(k \frac{\partial T}{\partial x}\right)}{\partial x}+\frac{\partial\left(k \frac{\partial T}{\partial y}\right)}{\partial y}+\frac{\partial\left(k \frac{\partial T}{\partial z}\right)}{\partial z}+q^{\prime}=\rho c_{p} \frac{\partial T}{\partial t}$

It is possible to write the heat conduction equation in the next form:

$\frac{\partial^{2} T}{\partial x^{2}}+\frac{\partial^{2} T}{\partial y^{2}}+\frac{\partial^{2} T}{\partial z^{2}}=\frac{1}{a} \frac{\partial T}{\partial t}$

Where, $q^{\prime}=0$ and $a=\frac{k}{\rho c_{p}}$, the thermal diffusivity $\left(\mathrm{m}^{2} / \mathrm{s}\right)$ : a measurement of the capacity of a medium to conduct thermal energy in relation with its capacity to store thermal energy.

In order to get the solution in a simple way, firstly we are going to get the solution for the one dimensional problem. The Green's function is a solution for the initial condition of an initial point source of heat at a certain position. The problem in one dimension is: 
$\frac{\partial^{2} T}{\partial x^{2}}=\frac{1}{a} \frac{\partial T}{\partial t}$

For the boundary conditions:

$-\infty<\mathrm{x}<\infty, 0<\mathrm{t}<\infty$

And $T\left(x-x^{\prime}, t=0\right)=\delta\left(x-x^{\prime}\right)$, where $\delta\left(x-x^{\prime}\right)$ is the Dirac delta function.

The solution to this problem is the fundamental solution (Green function):

$T\left(x-x^{\prime}, t\right)=\frac{Q^{\prime}}{\sqrt{4 \pi a t}} e^{-\frac{\left(x-x^{\prime}\right)^{2}}{4 a t}}$

We can check it in a simple form by doing the derivation in both sides of the head conduction equation in one dimension, where Q' has units of ( $\left.{ }^{\circ} \mathrm{k}-\mathrm{m}\right)$.

For $\mathrm{n}$ variables, the solution is the product of the fundamental solution in each variable:

$T\left(x-x^{\prime}, t\right)=\frac{Q^{\prime}}{(4 \pi a t)^{n / 2}} e^{-\frac{\left\{\left(x-x^{\prime}\right)^{2}+\left(y-y^{\prime}\right)^{2}+\cdots \cdots \cdots\right\}}{4 a t}}$

Where, Q' has units of $\left({ }^{\circ} \mathrm{k}-\mathrm{m}^{\mathrm{n}}\right)$.

In three dimensions, it has the next solution:

$T\left(x-x^{\prime}, t\right)=\frac{Q^{\prime}}{8(\pi a t)^{3 / 2}} e^{-\frac{\left\{\left(x-x^{\prime}\right)^{2}+\left(y-y^{\prime}\right)^{2}+\left(z-z^{\prime}\right)^{2}\right\}}{4 a t}}$

This expression has the zero value at all points when $t \rightarrow 0$ except in the point $x^{\prime}, y^{\prime}, z^{\prime}$ where it is infinite. In this expression, Q' $\left({ }^{\circ} \mathrm{k}-\mathrm{m}^{3}\right)$ corresponds to the temperature of an volume unit of the medium in which the quantity of heat is dissipated.

The total heat in the infinite region is given by:

$$
\begin{aligned}
\int_{-\infty}^{\infty} \int_{-\infty}^{\infty} \int_{-\infty}^{\infty} \rho C T d x d y d z & =\frac{Q^{\prime} \rho C}{8(\pi a t)^{3 / 2}} \int_{-\infty}^{\infty} e^{-\frac{\left(x-x^{\prime}\right)^{2}}{4 a t}} d x \int_{-\infty}^{\infty} e^{-\frac{\left(y-y^{\prime}\right)^{2}}{4 a t}} d y \int_{-\infty}^{\infty} e^{-\frac{\left(z-z^{\prime}\right)^{2}}{4 a t}} d z \\
& =\mathrm{Q}^{\prime} \rho \mathrm{C}
\end{aligned}
$$

Where, we used the result of the known integral for the integral in each coordinate:

$\int_{-\infty}^{\infty} e^{-b r^{2}} d r=\sqrt{\frac{\pi}{b}}$

Therefore, the solution corresponds to the temperature of an infinite solid due to the amount of heat Q'pc (J) instantaneously produced at $\mathrm{t}=0$ at a point $\mathrm{x}^{\prime}, \mathrm{y}^{\prime}, \mathrm{z}^{\prime}$. Namely, $\mathrm{T}$ is the temperature due to an instantaneous point source of intensity Q' at $\mathrm{t}=0$ and at the point $\mathrm{x}^{\prime}, \mathrm{y}^{\prime}, \mathrm{z}^{\prime}$.

If we replace $\left(x-x^{\prime}\right)^{2}+\left(y_{-} y^{\prime}\right)^{2}+\left(z-z^{\prime}\right)^{2}$ by $r^{2}$, after we derived the Green function solution in three dimensions respect to the time and it equal to zero (in order to get the time where there is a maximum value of the temperature of the wire), we obtain: 
$t=\frac{r^{2}}{6 a}$

Now, we are ready to get the equation for the temperature in a long thin wire carrying electric current embedded in a finite medium. We consider a distribution of instantaneous point sources of intensity Q'dz' at z' along the z axis, where Q' has unit of ${ }^{\circ} \mathrm{k}-\mathrm{m}^{2}$. We can obtain the temperature by the integration of the Green function:

$$
\begin{aligned}
& T\left(x-x^{\prime}, t\right)=\frac{Q^{\prime}}{8(\pi a t)^{3 / 2}} e^{-\frac{\left\{\left(x-x^{\prime}\right)^{2}+\left(y-y^{\prime}\right)^{2}+\left(z-z^{\prime}\right)^{2}\right\}}{4 a t}} \\
& T=\frac{Q^{\prime}}{8(\pi a t)^{3 / 2}} \int_{-\infty}^{\infty} e^{-\frac{\left\{\left(x-x^{\prime}\right)^{2}+\left(y-y^{\prime}\right)^{2}+\left(z-z^{\prime}\right)^{2}\right\}}{4 a t}} d z^{\prime} \\
& =\frac{Q^{\prime}}{4 \pi a t} e^{-\frac{\left(x-x^{\prime}\right)^{2}+\left(y-y^{\prime}\right)^{2}}{4 a t}}
\end{aligned}
$$

Therefore Q' $\rho c(\mathrm{~J} / \mathrm{m})$ is the heat dissipated per unit length of the line.

Now, we suppose that the heat is going to be dissipated at the rate $\rho c \varphi(t)(J /(m-s)$ per unit of length and per unit of time of a line parallel to the $\mathrm{z}$ axis and at the point $\mathrm{x}$, $\mathrm{y}^{\prime}$ [where $\varphi(\mathrm{t})$ has unit of $\left.\left({ }^{\circ} \mathrm{k}-\mathrm{m}^{2} / \mathrm{s}\right)\right]$.

The problem consists of searching of the temperature at a time $t$ after it is given heat to the medium at $t=0 \mathrm{~s}$. The solid at $\mathrm{t}=0 \mathrm{~s}$ has zero temperature and the source of heat is $\varphi(\mathrm{t})$. We can use the mathematical expression of the last equation in order to do the integration with respect to the time and with the substitution:

$r^{2}=\left(x-x^{\prime}\right)^{2}+\left(y-y^{\prime}\right)^{2}$

Therefore, we have:

$T=\frac{1}{4 \pi a} \int_{0}^{t} \varphi\left(t^{\prime}\right) e^{-\frac{r^{2}}{4 a\left(t-t^{\prime}\right)}} \frac{d t^{\prime}}{t-t^{\prime}}$

We consider $\varphi\left(\mathrm{t}^{\prime}\right)=\mathrm{Q}$ "' and constant, we obtain:

$T=\frac{Q^{\prime \prime}}{4 \pi a} \int_{\frac{r^{2}}{4 a t}}^{\infty} e^{-v} \frac{d v}{v}$

Where we did a change of variable:

$v=\frac{r^{2}}{4 a\left(t-t^{\prime}\right)}$

$u=\frac{r^{2}}{4 a t} \quad$ for the down limit in the integral

We have that the integral of the last equation is equal for small values of $\mathrm{r}^{2} /(4 \mathrm{at})$ to:

$$
\begin{aligned}
\int_{u}^{\infty} \frac{e^{-v}}{v} d v & =-\ln (C)-\ln (u)+u-\frac{1}{4} u^{2}-O\left(u^{3}\right) \\
& =\ln (1 / \mathrm{C})-\ln (\mathrm{u})+\mathrm{u}-\left(\mathrm{u}^{2} / 4\right)-\mathrm{O}\left(\mathrm{u}^{3}\right)
\end{aligned}
$$

Where, $\mathrm{C}=\mathrm{e}^{\gamma}, \gamma$ is the Euler constant $(0.5772 \ldots)$ and for large values of $\mathrm{t}$ or small values of $\mathrm{r}$, we have (by 
neglecting the last terms):

$T=\frac{Q^{\prime \prime}}{4 \pi a} \ln \left(\frac{1}{C u}\right)$

It is very important to mention that for our hot wire technique, we use a wire with a very small diameter in order to valid the small values of $r^{2} /(4 a t)$. Thus, we have by replacing $u=r^{2} /(4 a t)$ :

$T=\frac{Q^{\prime \prime} \ln \left(\frac{4 a t}{C r^{2}}\right)}{4 \pi a}$

If we replace $\mathrm{a}=\mathrm{k} /\left(\rho \mathrm{C}_{\mathrm{p})}\right.$ for the first $\mathrm{a}$, we have:

$T=\frac{Q^{\prime \prime} \rho \operatorname{Cp} \ln \left(\frac{4 \mathrm{at}}{\mathrm{Cr}^{2}}\right)}{4 \pi k}$

Finally, we do the substitution of $Q$ ' $\rho C_{p}$ by $Q$ : the power applied per unit of length $(\mathrm{J} / \mathrm{m}-\mathrm{s})$. We obtain:

$T=\frac{Q \ln \left(\frac{4 a t}{C r^{2}}\right)}{4 \pi k}$

In summary, we have:

Q: heat flux per unit of length $(\mathrm{J} / \mathrm{m}-\mathrm{s}) \mathrm{k}$ : thermal

conductivity $\left(\mathrm{J} /\left(\mathrm{m}-\mathrm{s}-{ }^{\circ} \mathrm{k}\right)\right)$

$a:$ thermal diffusivity $\left(\mathrm{m}^{2} / \mathrm{s}\right)$

r: radius of the wire

C: constant given by the exponent of Euler: $C=e^{\gamma}$ where $\gamma=0.577$

\section{Analysis of the Corrections to the Formula of the Hot Wire}

The corrections can be expressed as follow:

$\Delta T=\Delta T_{w}+\sum \partial T$

Where:

$\Delta \mathrm{T}_{\mathrm{W}}:$ measured temperature change

$\partial \mathrm{T}$ : corrections to the temperature change

\subsection{Corrections due to the finite extent of the fluid}

The correction for the finite extent of the fluid was analyzed by Healy [4]. Is is given by the next formula:

$\partial T=\frac{Q}{4 \pi k}\left[\ln \left(\frac{4 a t}{C\left(2 r_{c e l l}\right)^{2}}\right)+\sum_{u=1}^{\infty} e^{\frac{-g u^{2} a t}{\left(2 r_{c e l l}\right)^{2}}}\left(\pi Y_{o} g_{u}\right)^{2}\right]$

Where, $Y_{O}$ is the zero order Bessel function of the second type, $g_{u}$ are the roots of $J_{O}$ (where $J_{O}$ is the zero order Bessel function of the first type). 


\subsection{Corrections due to the finite physical properties of the wire and the insulating layer}

Nagasaka and Nagashima analyzed this correction and obtained the next expression [1]:

$$
\delta T=-\frac{Q}{4 \pi k}\left[\ln \left(\frac{r_{w}}{r_{c}}\right)^{2}+\frac{2 k}{k_{c}} \ln \left(\frac{r_{c}}{r_{w}}\right)+\frac{k}{k_{c}}+\frac{1}{t}\left(A_{1}+A_{2}+A_{3} \ln \left(\frac{4 a t}{C r_{C}{ }^{2}}\right)\right.\right.
$$

Where:

$A_{1}=\frac{r_{w}^{2}}{8}\left[\left(\frac{k-k_{C}}{k_{W}}\right)\left(\frac{1}{a_{w}}-\frac{1}{a_{C}}\right)+\frac{4}{a_{C}}-\frac{2}{a_{W}}\right]$

$A_{2}=\frac{r_{C}^{2}}{2}\left(\frac{1}{a}-\frac{1}{a_{C}}\right)+\frac{r_{w}^{2}}{k_{C}}\left(\frac{k_{C}}{a_{C}}-\frac{k_{w}}{a_{w}}\right) \ln \left(\frac{r_{C}}{r_{w}}\right)$

$A_{3}=\frac{r_{w}^{2}}{2 k}\left(\frac{k_{C}}{a_{C}}-\frac{k_{w}}{a_{w}}\right)+\frac{r_{C}^{2}}{2 k}\left(\frac{k}{a}-\frac{k_{w}}{a_{w}}\right)$

Where, the subscripts w,c are related to the wire and the coating, no subscript is related to the liquid. Besides, Q: heat flux per unit of length, $\mathrm{k}$ : thermal conductivity, $a$ : thermal diffusivity, $\mathrm{r}$ : radius, $\mathrm{C}$ : constant given by the exponent of Euler constant $\mathrm{C}=\mathrm{e}^{\gamma}$ where $\gamma=0.577$.

We can analyze this expression in order to obtain the effects of the coating. If the term (1/t) $\left[\mathrm{A}_{1}+\mathrm{A}_{2}+\mathrm{A}_{3} \ln \left(4 \mathrm{at}_{\mathrm{c}} / \mathrm{r}_{\mathrm{c}}{ }^{2} \mathrm{C}\right)\right]$ is very small respect to the remaining terms, then the coating affects the expression with the shifts of the plot but without changing the slope. Namely, it don't affects the value of the thermal conductivity. It was verified by $\mathrm{Yu}$ and Choi experimentally. They analyzed the wire temperature rise as a function of time, and they concluded that the error is neglected if the taking data starts a little later of the beginning of the experiment.

\subsection{Corrections to the heat loss due to the radiation}

Finally, the correction due to the heat loss by radiation is taken in account. It was derived by Nieto de Castro [5] and it is given by the expression:

$\partial T=\frac{-Q H_{r}}{4 \pi k}\left(\frac{r_{w}^{2}}{4 a} \ln \left(\frac{4 a t}{C r_{w}{ }^{2}}+\frac{r_{w}^{2}}{4 a}-t\right)\right)$

Where, $\mathrm{H}_{\mathrm{r}}$ is determined by using the last equation (after we do the corrections for the finite extents of the fluid, the finite physical dimensions of the wire and the insulating layer):

$\Delta T=\Delta T_{w}-\partial T$

Where:

$\Delta T_{w}=\frac{Q}{4 \pi k} \ln \left(\frac{4 a t}{r^{2} C}\right)$

Therefore, we can observe the errors of the experiment with the standard liquids and therefore we can obtain the value of $\mathrm{H}_{\mathrm{r}}$. In order to know if the heat loss by radiation is necessary to take in account, we need to do some calculations. From the formula: 
$Q=\frac{V_{w}{ }^{2}}{L R}$

Where:

$\mathrm{V}_{\mathrm{W}}$ is in the order of $0.5 \mathrm{~V}, \mathrm{~L}=44.3 \mathrm{~cm}$ (wire length) and $\mathrm{R}$ is in the order of 0.1-0.5 $\Omega$ (wire resistance), we obtain that $\mathrm{Q}$ is approximately in the order of $1.12 \mathrm{~W} / \mathrm{m}$. Now, we are going to do the calculations for the heat loss by radiation:

$q_{r}=\varepsilon \sigma\left(T_{w}{ }^{4}-T_{o}{ }^{4}\right) A$

Where, $\mathrm{T}_{\mathrm{W}}$ is the temperature of the wire, $\mathrm{T}_{\mathrm{O}}$ is the temperature of the fluid (outside of the wire), $\varepsilon$ is the emissivity coefficient (more than 0 and less than 1: a value that it reflects the efficiency of the energy emission of a surface respect to the black body), $\varepsilon$ for Platinum at $1000{ }^{\circ} \mathrm{C}$ is 0.57 .

$\sigma=5.67 * 10^{-8} \mathrm{~W} / \mathrm{m}^{2} \mathrm{~K}^{4}$

If we consider the values: $\mathrm{T}_{\mathrm{W}}=1278{ }^{\circ} \mathrm{K}, \mathrm{T}_{\mathrm{O}}=1273{ }^{\circ} \mathrm{K}$ and $A=\pi r^{2} \quad\left(\mathrm{r}_{\mathrm{W}}=125 \mu \mathrm{m}\right)$, we obtain that $\mathrm{qr}$ is approximately $0.000066 \mathrm{~W}$. It is very small in comparison with the heat loss by conduction. Therefore, we can conclude that heat loss by radiation can be neglected. It is in the order of approximately $0.01 \%$ [(qr/QL $) * 100]$.

\section{Theoretical and Practical Considerations}

We do the next considerations:

- The constant ideal heat generation source is due to a thin continuous line-wire $(r \approx 0)$ with an infinitely length and dissipating heat into an infinite medium.

- The power is applied briefly and abruptly (transient technique).

- The convective heat transport is minimized in the brief period of measurement time.

- The heat transferred to the medium is due to the conduction only.

- The Fourier equation for 1D transient heat conduction is used for the theoretical solution:

\section{Fourier Equations}

$$
\begin{array}{lc}
\rho_{P t} C_{P t} \frac{\partial T}{\partial t}=\frac{1}{r} \frac{\partial\left(r K_{P t} \frac{\partial T}{\partial r}\right)}{\partial r}+q^{\prime} & \text { Platinum wire } \\
\rho_{L} C_{L} \frac{\partial T}{\partial t}=\frac{1}{r} \frac{\partial\left(r K_{L} \frac{\partial T}{\partial r}\right)}{\partial r} & \text { Medium }
\end{array}
$$

\section{Initial Conditions and Boundary Conditions}

$$
\begin{array}{lllll}
\mathrm{t}=0 & \mathrm{~T}=\mathrm{T}_{\mathrm{o}} & \mathrm{r}=\mathrm{R} & K_{P t} \frac{\partial T}{\partial r}=K_{L} \frac{\partial T}{\partial r} & \mathrm{~T}_{\mathrm{Pt}}=\mathrm{T}_{\mathrm{L}} \\
\mathrm{r}=0 & \frac{\partial T}{\partial r}=0 & \mathrm{r}=\infty & \mathrm{T}=\mathrm{T}_{\mathrm{o}}
\end{array}
$$

Where: $\rho, \mathrm{C}, \mathrm{K}$ are the density, specific heat and the thermal conductivity. The subscripts $\mathrm{Pt}$ and $\mathrm{L}$ are for the 
Platinum and for the fluid respectively and $r$ is the radius of the Platinum, $q^{\prime}$ is the heat source $\left(\mathrm{W} / \mathrm{m}^{3}\right)$ and $\mathrm{T}_{\mathrm{o}}$ is the initial Temperature.

By working out the Fourier equation with the initial and the boundary conditions:

$\Delta T=T(r, t)-T_{o}=\frac{Q}{4 \pi K_{L}}\left[\ln \frac{4 K_{L} t}{C \rho C_{p} r^{2}}+\frac{\rho C_{p} r^{2}}{4 K_{L} t}-\frac{r^{4} \rho^{2} C_{p}^{2}}{64 K_{L}^{2} t^{2}}+O\left(\frac{\rho C_{p} r^{2}}{4 K_{L} t}\right)\right.$

For larger values of $t$ and small values of $r$, the last terms are neglected, and we have:

$\Delta T=\frac{Q \ln \left(\frac{4 a t}{C r 2}\right)}{4 \pi k}$

Where: $\quad a=\frac{K}{\rho C_{p}}$

For an interval of time and for any fixed radial distance:

$T=\frac{Q}{4 \pi k}\left[\ln (t)+\ln \left(\frac{4 a}{r^{2} C}\right)\right]$

Where:

$\mathrm{Q}$ is the heat flux per unit of length $(\mathrm{J} / \mathrm{m}-\mathrm{s})$

$\mathrm{k}$ is the thermal conductivity $\left(\mathrm{J} / \mathrm{m}-\mathrm{s}-{ }^{\circ} \mathrm{k}\right)$

$a$ is the thermal diffusivity $\left(\mathrm{m}^{2} / \mathrm{s}\right)$

$r$ is the radius of the wire

$\mathrm{C}$ is the constant given by the exponent of Euler, $\mathrm{C}=\mathrm{e}^{\gamma}$ where $\gamma=0.577$

From the slope of the graphic $\mathrm{T}$ versus $\ln (\mathrm{t})$, we have:

$k=\frac{Q}{4 \pi m}$

Where, $\mathrm{m}$ is the slope of the curve.

From the Intersection with the $\mathrm{t}$ axis $(\mathrm{T}=0)$ :

$\ln (a)=\left(\ln \frac{r^{2} C}{4}-\ln t_{o}\right)$

The approximation of the ideal case of the continuous line with an infinitely length is with a thin wire with a long length located in a finite medium. The measurement of the temperature change of the wire is at short interval of times (transient method). Therefore, the physical properties are assumed to be constants because of the short time period of measurement.

In practice, there are small deviations because of the effects of the finite length of the wire and the finite medium. Also, there is an initial deviation at the beginning of the experiment and so the Fourier equation without truncated higher order terms is not valid at this period of time (transient period). The longitudinal heat decreases/increases produce deviations from the uniform temperature profile of concentric isotherms around of the wire. Besides, the 
fraction of the input power to be stored by the wire is effective at small times and the effects of the finite dimensions appear at large times with the possibility of convective heat transport and mass transfer too. The solution is to consider a time windows (measurement between $t_{\min }$ and $t_{\max }$ ). This time windows can be identified

by looking the plot of $T$ versus $\ln (\mathrm{t})$. The corrections to the equation $T(r, t)=\frac{Q \ln \left(\frac{4 a t}{r^{2} C}\right)}{4 \pi k}$ can be expressed as follow:

$\Delta T=\Delta T_{w}+\sum \partial T$

Where:

$\Delta \mathrm{T}_{\mathrm{w}}:$ measured temperature change

$\partial \mathrm{T}: \quad$ corrections to the temperature change

The necessity of the coating of the hot wire was established by Nagasaka and Nagashima [1]. The reasons were:

- Polarization of the thin wire surface.

- Possible current flow through the medium (depending of the liquid). It gives error in the measurement of the heat generated in the wire

- Influence of the conducting liquid cell. It produces possible distortion of the output voltage signal.

The solution is to coat the wire with an electrically insulting material (Teflon, ceramic, etc). The correction formula was presented in the item 4.2. The coating affects the formula $T(r, t)=\frac{Q \ln \left(\frac{4 a t}{r^{2} C}\right)}{4 \pi k}$ with the shifts of the plot but without changing the slope. Thus, it doesn't affect the value of the thermal conductivity. Yu and Choi analyzed the wire temperature rise as a function of time, and they concluded that the error is neglected if the taking data starts a little later of the beginning of the experiment. It also was verified experimentally at this research with copper insulated with Teflon. The corrections due to the finite extent of the fluid was analyzed by Healy [4] and the formula was presented at the item 4.1. The corrections for the heat loss due to the radiation was given by Nieto de Castro [5] and his formula was presented at the item 4.3. It is also estimated that the heat dissipation by radiation can be neglected.

\section{Numerical Simulations}

The wire and the sample don't have the ideal dimensions of the theoretical model. The numerical analysis is very important in order to analyze the dependence of the thermal conductivity with the dimensions. Besides, it is important to calculate the thermal conductivity and to compare with the exact value of the thermal conductivity of the liquid and to calculate the errors due to the finite dimensions.

The model is a symmetrical cylinder and we consider only the quarter part of the system for the numerical calculations of the temperature. There are symmetrical conditions in the $2 \mathrm{D}$ system. The heat transferred to the infinite medium is only by conduction effect (1D). The Fourier equations, boundary conditions and the initial conditions were given at the item 5 . 


\subsection{Numerical Simulation for tungstates at high temperature (1)}

We have the next considerations:

- Software: Fluent

- Mesh: 10000*2 (quadrangles)

- Different radius of the wire: $50 \mu \mathrm{m}, 125 \mu \mathrm{m}, 175 \mu \mathrm{m}$

- Wires radius/sample radius: 1/100 (constant)

- $\mathrm{h}($ wire $)=\mathrm{r}($ wire $)$

- Temperature: $1000^{\circ} \mathrm{k}$

- Axial symmetry and transient time conditions

- Physical properties are independent of the temperature

The mesh for the wire with radius of $175 \mu \mathrm{m}$ (1/100 constant) is:

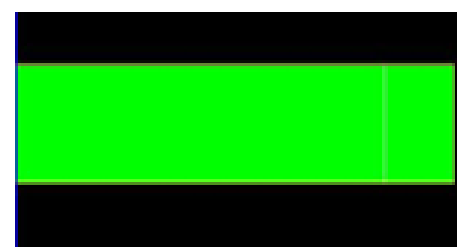

Fig.4 Mesh for Tungstate at High Temperature (1)

The curve of temperature versus time with the time step of $0.01 \mathrm{~s}$ is:

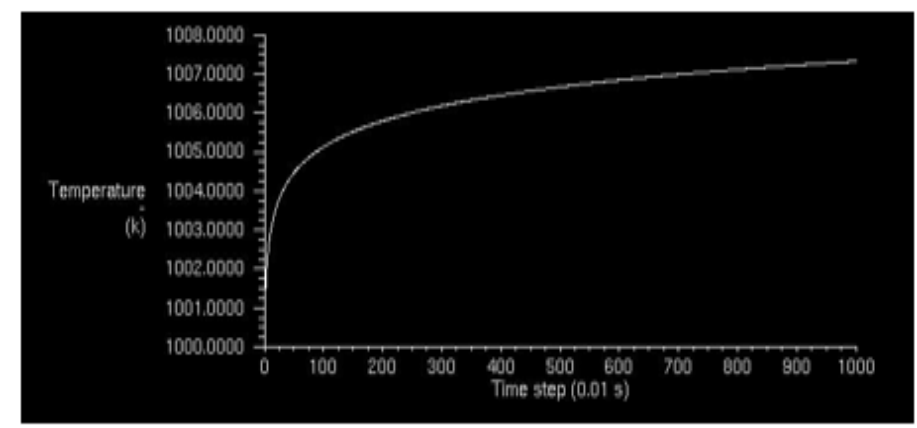

Fig.5 Temperature versus Time for Tungstate at High Temperature (1)

It is possible to see the logarithmic pattern. The variations of temperature are from 1 to $10\left({ }^{\circ} \mathrm{K}\right)$. The static temperature $\left({ }^{\circ} \mathrm{K}\right)$ versus position $(\mathrm{m})\left(\mathrm{r}_{\mathrm{w}}=175 \mu \mathrm{m}\right)$ is:

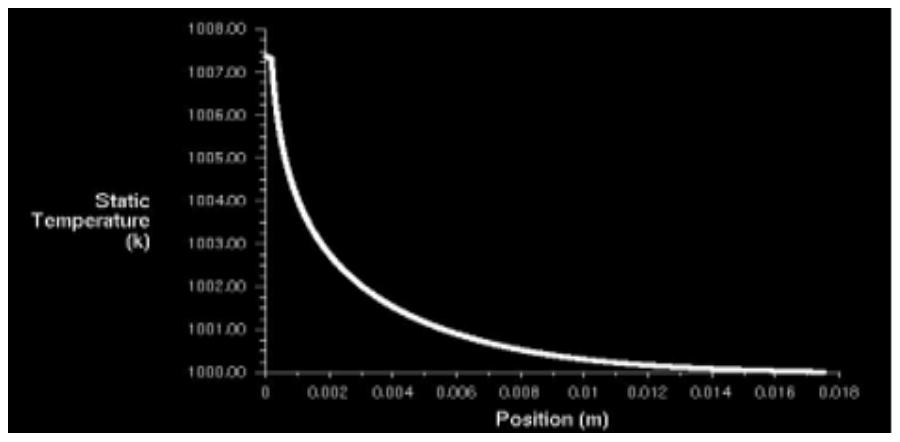

Fig.6 Static Temperature versus Position for Tungstate at High Temperature (1) 
It is possible to see the logarithmic pattern. The variations of temperature are from 1 to $10\left({ }^{\circ} \mathrm{K}\right)$. The static temperature $\left({ }^{\circ} \mathrm{K}\right)$ versus position $(\mathrm{m})\left(\mathrm{r}_{\mathrm{w}}=175 \mu \mathrm{m}\right)$ is:

We can see the temperature increase in the wire and its conduction to the liquid.

The contourns of the temperature in the y direction is:

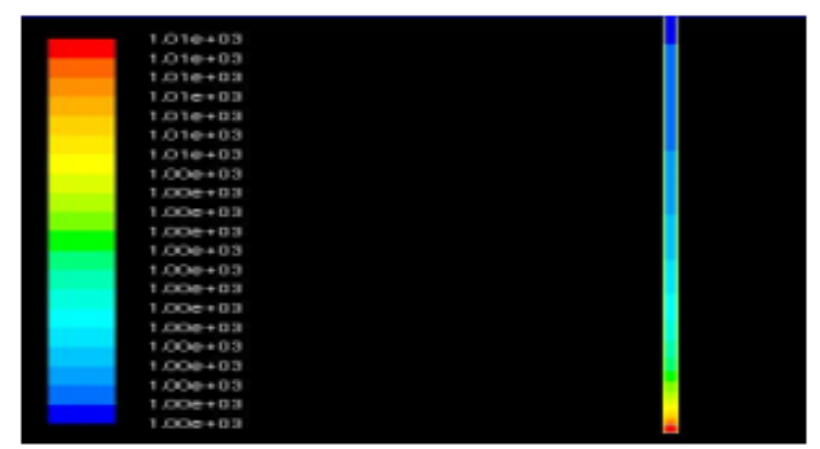

Fig.7 Contourns of the Temperature in Y Direction for Tungstate at High Temperature (1).

The plot of $\Delta \mathrm{T}$ versus $\ln (\mathrm{t})$ is:

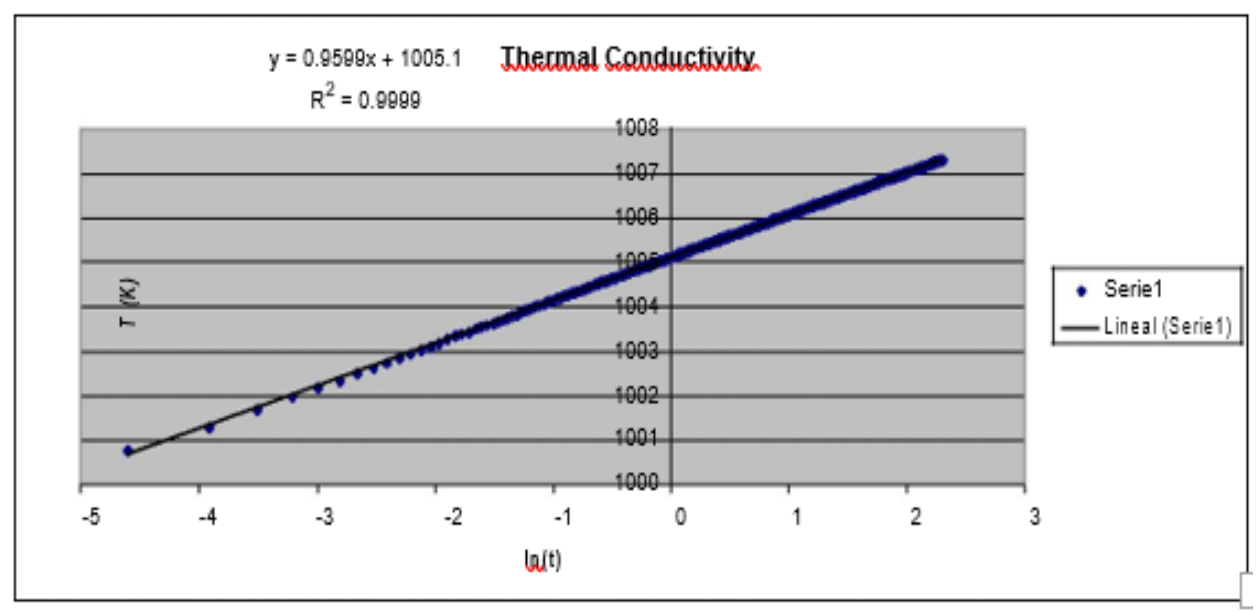

Fig.8 Plot of $\Delta \mathrm{T}$ versus $\ln (\mathrm{t})$ for Tungstate at High Temperature (1)

It is possible to observe a very clear linear relation of the plot and from the slope we can obtain $\mathrm{k}$, the thermal conductivity. The results are summarized in the next table:

\begin{tabular}{|r|r|r|}
\hline$q^{\prime}=$ & $5.00 E+08$ & $\mathrm{~W} / \mathrm{m3}$ \\
\hline $\mathrm{r}=$ & 0.000175 & $\mathrm{~m}$ \\
\hline $\mathrm{A}=$ & $9.62 \mathrm{E}-08$ & $\mathrm{~m} 2$ \\
\hline $\mathrm{Q}=$ & $4.81 \mathrm{E}+01$ & $\mathrm{~W} / \mathrm{m}$ \\
\hline $\mathrm{m}=$ & 0.9599 & ${ }^{\circ} \mathrm{k}$ \\
\hline $\mathrm{k}=$ & 3.988 & $\mathrm{~W} / \mathrm{m}-{ }^{\circ} \mathrm{K}$ \\
\hline $\mathrm{E}=$ & 1.772 & $\%$ \\
\hline
\end{tabular}

Table 2: Summary of calculations of the thermal conductivity for tungstate (1) where $\mathrm{k}($ reference $)=4.06 \mathrm{~W} / \mathrm{m}-{ }^{\circ} \mathrm{k}$. 
The table of the numerical analysis of the dimensions of the hot wire is presented:

\begin{tabular}{|c|c|c|c|}
\hline$R_{\text {cell }}(\mu \mathrm{m})$ & $r(\mu m)$ & $\mathrm{k}(\mathrm{W} / \mathrm{m} \cdot \mathrm{K})$ & $E(\%)$ \\
\hline 5000 & 50 & 3.27 & 19.31 \\
\hline 12500 & 125 & 3.79 & 6.55 \\
\hline 17500 & 175 & 3.99 & 1.77 \\
\hline $\begin{array}{l}\text { k(refe rence) } \\
\text { (tugnstate) }\end{array}$ & 4.06 & $W / m-\circ \mathrm{K}$ & \\
\hline
\end{tabular}

Table 3: Numerical analysis of the hot wire for tungstate (1)

Where:

$\mathrm{T}=1000^{\circ} \mathrm{k}$

$\mathrm{h}_{\text {wire }}=\mathrm{r}_{\text {wire }}$

$\mathrm{r}_{\text {wire }} / \mathrm{R}_{\text {medium }}=1 / 100$ (constant)

The effects of the dimensions are lower when the radius of the medium ( $\mathrm{R}_{\text {cell }}$ or $\left.\mathrm{R}_{\text {medium }}\right)$ is the highest. The effects of the increase of the radius of the medium prevails over the decrease of the radius of the wire for a constant rate $r_{\text {wire }} / R_{\text {medium. }}$ It is possible to observe in the correction formulas.

\subsection{Numerical Simulation for tungstates at high temperature (2)}

We have the next considerations:

- Mesh: 10000*2 (quadrangles)

- Radius of the wire: $175 \mu \mathrm{m}$

- Wires radius/sample radius: 1/5, 1/100 (constant)

- $\quad \mathrm{h}($ wire $)=\mathrm{r}($ wire $)$

- Temperature: $1000{ }^{\circ} \mathrm{k}$

- Axial symmetry and transient time conditions

- Physical properties are independent of the temperature

It is obtained the next table of results:

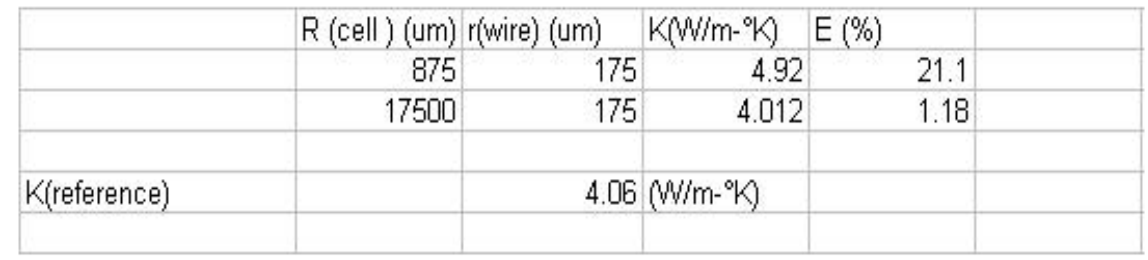

Table 4: Numerical analysis of dimensions of the hot wire with $r=175 \mu \mathrm{m}$ and for tungstate (2)

Where: $\mathrm{T}=1000^{\circ} \mathrm{k} \quad \mathrm{h}_{\text {wire }}=\mathrm{r}_{\text {wire }}$ 
It is evident at this analysis that when the radius of the cell (medium) increases the error due to the effect of the dimensions decrease. Thus, it is better to choose the best configuration:

$\mathrm{r}_{\text {wire }} / \mathrm{R}_{\text {medium }}=1 / 100$ (constant) $\quad \mathrm{r}_{\text {wire }}=175 \mu \mathrm{m}$

\subsection{Numerical Simulations with other liquids}

We have the next considerations:

- Mesh: 10000*2 (quadrangles)

- $\quad$ Radius of the wire: $175 \mu \mathrm{m}$

- Wires radius/sample radius: 1/100 (constant)

- $\quad h($ wire $)=r($ wire $)$

- Temperature: $20^{\circ} \mathrm{C}\left(293^{\circ} \mathrm{k}\right)$

- Axial symmetry and transient time conditions

- Physical properties are independent of the temperature

\subsubsection{Results}

The plot of $\mathrm{T}\left({ }^{\circ} \mathrm{k}\right)$ versus time step $(0.01 \mathrm{~s})$ is showed for water deionized:

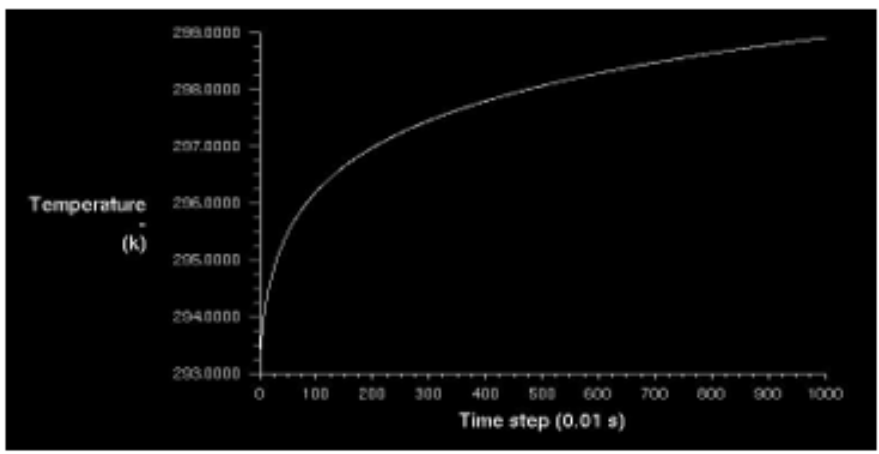

Fig.9 Temperature versus Time for Water Deionized

It is possible to see the logarithmic pattern. The temperature variations are from 1 to $10^{\circ} \mathrm{k}$.

The static temperature $\left({ }^{\circ} \mathrm{k}\right)$ versus position $(\mathrm{m})$ is presented in the next plot:

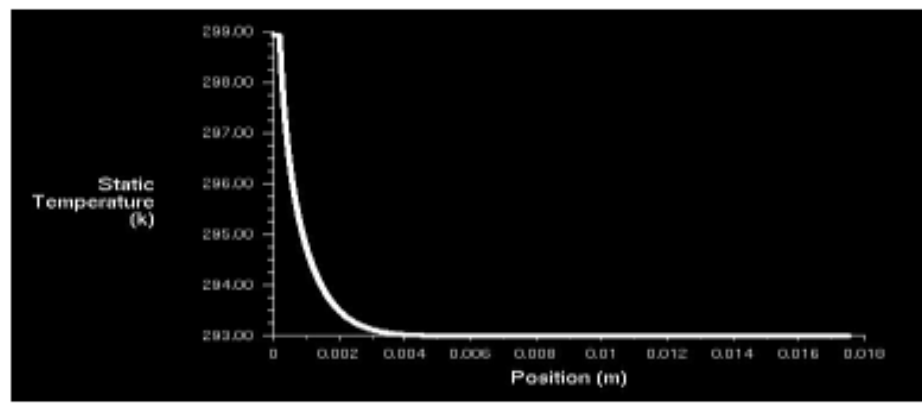

Fig.10 Static Temperature versus Position for Water Deionized 
We can see the temperature increase in the wire and its conduction to the liquid. The figure of the contours of the temperature in the y direction is also showed:

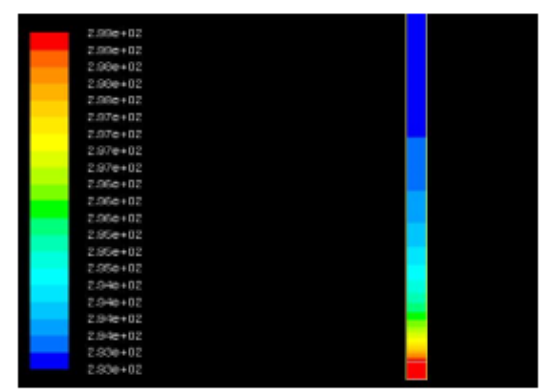

Fig.11 Contourns of the Temperature in Y Direction for Water Deionized

Finally, we have the plot of $\Delta \mathrm{T}$ versus $\ln (\mathrm{t})$ :

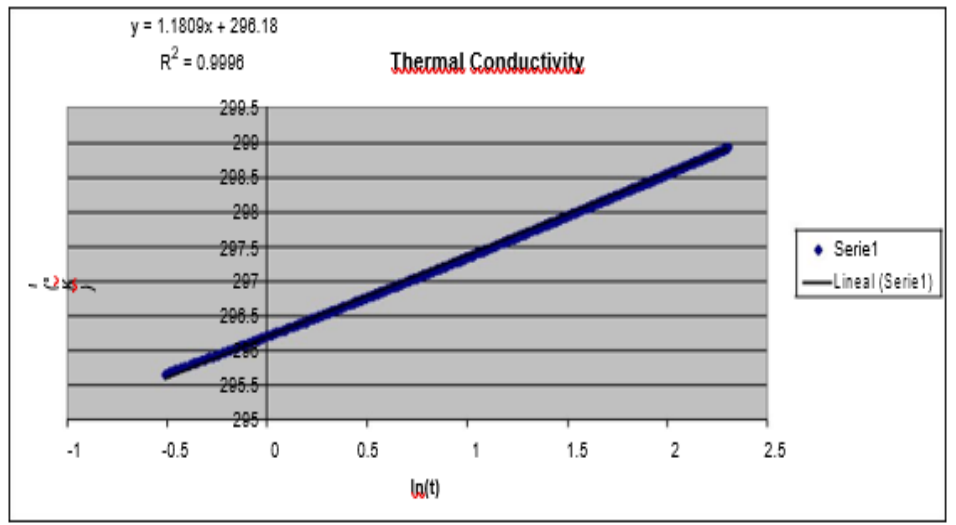

Fig.12 Plot of $\Delta \mathrm{T}$ versus $\ln (\mathrm{t})$ for Water Deionized

It is possible to observe a very clear linear relation and from the slope we can obtain $\mathrm{k}$, the thermal conductivity.

The summary table is as follow:

\begin{tabular}{|r|r|r|}
\hline $\mathrm{q}^{\prime}=$ & $1.00 \mathrm{E}+08$ & $\mathrm{~W} / \mathrm{m} 3$ \\
\hline $\mathrm{r}=$ & 0.000175 & $\mathrm{~m}$ \\
\hline $\mathrm{A}=$ & $9.62 \mathrm{E}-08$ & $\mathrm{~m} 2$ \\
\hline $\mathrm{Q}=$ & 9.62 & $\mathrm{~W} / \mathrm{m}$ \\
\hline $\mathrm{m}=$ & 1.181 & ${ }^{\circ} \mathrm{k}$ \\
\hline $\mathrm{k}=$ & 0.648 & $\mathrm{~W} / \mathrm{m}-{ }^{\circ} \mathrm{K}$ \\
\hline $\mathrm{E}=$ & 6.81 & $\%$ \\
\hline
\end{tabular}

Table 5: Summary table of calculations of the thermal conductivity for water deionized

Where, the $\mathrm{k}_{\text {reference }}=0.607 \mathrm{~W} / \mathrm{m}-{ }^{\circ} \mathrm{k}$

The table of the thermal conductivity for different liquids is:

\begin{tabular}{|l|r|r|r|}
\hline & & & \\
\hline & water deionized & acetone & ethylene glycol \\
\hline $\mathrm{k}\left(\mathrm{W} / \mathrm{m}-{ }^{\circ} \mathrm{K}\right)$ & 0.648 & 0.182 & 0.27 \\
\hline $\mathrm{k}(\mathrm{reference})\left(\mathrm{W} / \mathrm{m}-{ }^{\circ} \mathrm{K}\right)$ & 0.607 & 0.18 & 0.252 \\
\hline $\mathrm{E}(\%)$ & 5.8 & 1.5 & 7.3 \\
\hline & & & \\
\hline
\end{tabular}

Table 6: Results of the thermal conductivity for different liquids 
Where:

$\mathrm{T}=20^{\circ} \mathrm{k}$

$\mathrm{r}_{\text {wire }}=175 \mu \mathrm{m}$

$\mathrm{h}_{\text {wire }}=\mathrm{r}_{\text {wire }}$

$\mathrm{r}_{\text {wire }} / \mathrm{r}_{\text {medium }}=1 / 100$

We can observe that the errors are lower than $8 \%$.

\section{Experimental method and results}

The experimental set-up was presented in the figure 1 . We take in account the next considerations:

- The wire is heated by applying an electrical current from a constant power supply.

- The wire is a heated source which produces a time dependent temperature field within the liquid.

- The time of measurement is very short. Thus, the convection effect can be minimized.

- The temperature increase of the wire is due to the conduction heating.

- Therefore, the change in resistance of the wire is because of the temperature increase.

- The wire acts as heat source and temperature sensor.

- The thermal conductivity is obtained from the slope of the formula of the $\Delta T$ versus $\ln (t)$.

- The wire is located in the testing container which is filled with the respective liquid of interest.

- The PC controls the time, signal measurement and processing data.

- The DC power source provides the current source which is applied for a short time on the wire through a Wheatstone bridge.

- The Data Acquisition System measures the signals from the wire (voltage out and temperature) by using the Lab-View Software.

- We can obtain the resistance change by using the Wheatstone bridge and applying the divisor voltage equation.

$\Delta R w=\frac{R_{3}\left[\left(R_{2}+R_{p}\right) \frac{V_{\text {out }}}{V_{\text {in }}}+R_{p}\right]}{\left[R_{2}-\left(R_{2}+R_{p}\right) \frac{V_{\text {out }}}{V_{\text {in }}}\right]}-R w o$

- Afterward, we can apply the Calendar equation to convert resistance to temperature.

$$
\Delta T=\frac{\Delta R_{w}}{a R_{w o}}
$$

- Finally, we can obtain the thermal conductivity $\mathrm{K}\left(\mathrm{W} / \mathrm{m}^{-}{ }^{\circ} \mathrm{k}\right)$ from the slope of $\Delta \mathrm{T}$ versus $\ln (\mathrm{t}): k=\frac{\mathrm{Q}}{4 \pi \mathrm{m}}$

\subsection{Experimental values of the Design of the Hot Wire}

We use the next values for the design:

$\mathrm{L}_{\mathrm{w}}=37 \mathrm{~cm}(\mathrm{w}:$ wire $)$

$\mathrm{r}_{\mathrm{w}}=175 \mu \mathrm{m}$

$\mathrm{r}_{\mathrm{m}}=5 \mathrm{~cm} \quad(\mathrm{~m}:$ medium $)$ 
$\mathrm{h}_{\mathrm{m}}=12.5 \mathrm{~cm}$

$\mathrm{r}_{\mathrm{w}} / \mathrm{r}_{\mathrm{m}}=0.0035$

$\mathrm{R}_{\mathrm{w}}=1 \Omega$

$\rho=25.98 \mu \Omega-m \quad \rho=R_{w} A / L_{w}$

Where: $\mathrm{A}$ is the cross sectional area of the wire $\left(\mathrm{cm}^{2}\right)$

$\rho$ is the resistivity of the wire (measured in $\mu \Omega-\mathrm{m}$ )

$\mathrm{R}_{\mathrm{w}}$ is the electrical resistance of the wire $(\mu \Omega)$

$\mathrm{L}_{\mathrm{w}}$ is the length of the wire $(\mathrm{cm})$

The method to obtain $\mathrm{k}: k=\frac{\mathrm{Q}}{4 \pi \mathrm{m}}$, the design and the values of the resistance of the wheatstone bridge and the coefficient of the Calendar equation were given at the item 1 and 2 .

\subsection{Result for ethylene glycol}

The plot of $\Delta \mathrm{T}$ versus $\ln (\mathrm{t})$ is:

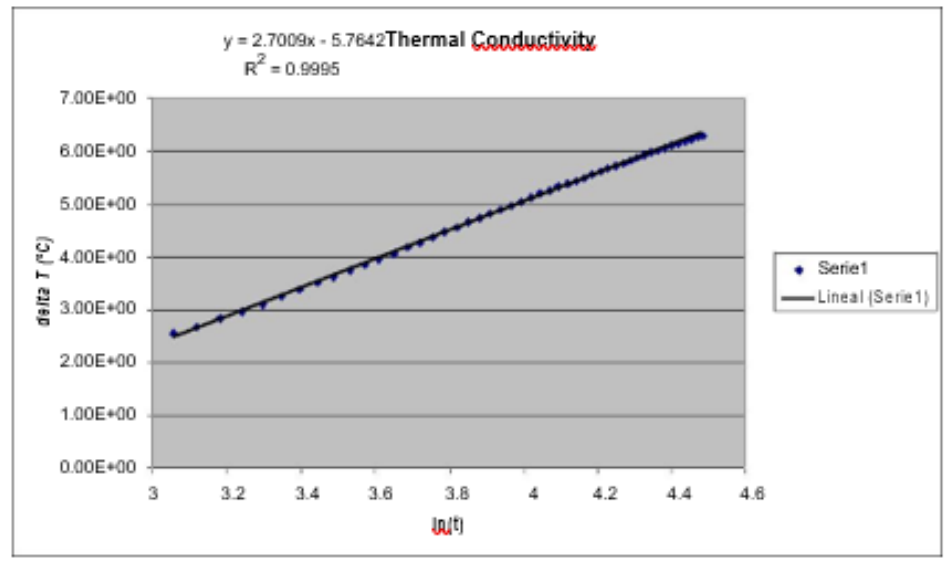

Fig.13 $\Delta \mathrm{T}$ versus $\ln (\mathrm{t})$ for Ethylene Glycol (experiment)

The table of the calculation of the thermal conductivity $\mathrm{k}$ is:

\begin{tabular}{|c|c|c|c|c|c|}
\hline$q^{\prime}=$ & 1.11E+01 & $\mathrm{W} / \mathrm{m}$ & & & \\
\hline \multirow[t]{3}{*}{$m=$} & 2.7009 & ${ }^{\circ} \mathrm{C}$ & Kreference $\left(W / m-{ }^{\circ} \mathrm{C}\right)$ & 0.34 & \\
\hline & & & & & \\
\hline & & & $\mathrm{K}\left(\mathrm{W} / \mathrm{m} \cdot{ }^{\circ} \mathrm{C}\right)=$ & 0.32622822 & \\
\hline & & & & & \\
\hline $\mathrm{K}\left(W / \mathrm{m} \cdot{ }^{\circ} \mathrm{C}\right)=$ & $q^{\prime} /\left(4^{*} 3.14^{*} \mathrm{~m}\right)$ & & $E=$ & 2.94 & $\%$ \\
\hline
\end{tabular}

Table 7: Calculations of the thermal conductivity for ethylene glycol (experiment)

The error is less than $3 \%$ and the reference value of the thermal conductivity is $\mathrm{k}=0.34 \mathrm{~W} / \mathrm{m}-{ }^{\circ} \mathrm{C}$.

\subsection{Result for water deionized}

We have the next plot of $\Delta \mathrm{T}$ versus $\ln (\mathrm{t})$ : 


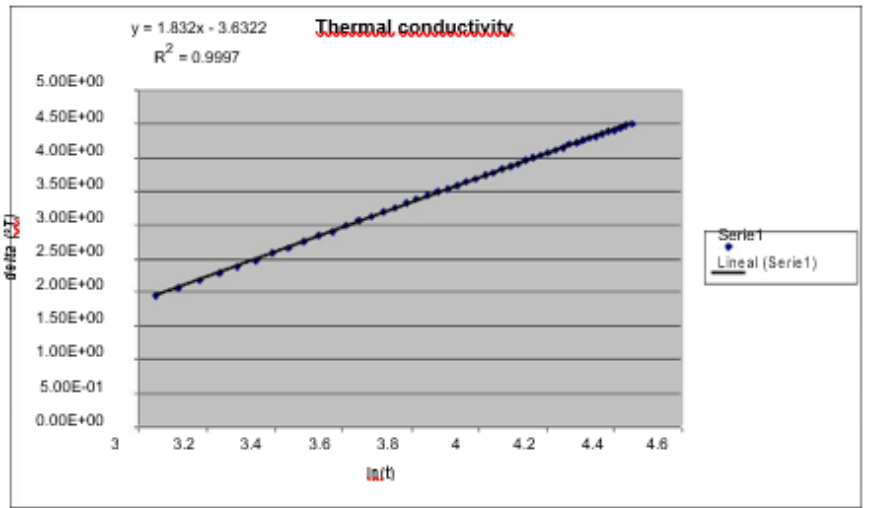

Fig.14 $\Delta \mathrm{T}$ versus $\ln (\mathrm{t})$ for Water Deionized (experiment)

And the table of the thermal conductivity is as follow:

\begin{tabular}{|l|r|l|l|l|}
\hline & & & \\
\hline$q=$ & $1.52 E+01$ & $W / m$ & Kreference $\left(W / m-{ }^{\circ} \mathrm{C}\right)$ & 0.61 \\
\hline$m=$ & $1.832{ }^{\circ} \mathrm{C}$ & & \\
\hline & & & $K\left(W / m \cdot{ }^{\circ} \mathrm{C}\right)=$ & 0.6594746 \\
\hline $\mathrm{K}\left(\mathrm{W} / \mathrm{m} \cdot{ }^{\circ} \mathrm{C}\right)=$ & $\mathrm{q}^{\prime} /\left(4^{*} 3.14^{*} \mathrm{~m}\right)$ & $\mathrm{E}=$ & $6.55737705 \%$ \\
\hline
\end{tabular}

Table 8: Calculations of the thermal conductivity for water deionized (experiment)

The error is less than $10 \%$ and the reference value of the thermal conductivity is $\mathrm{k}=0.66 \mathrm{~W} / \mathrm{m}-{ }^{\circ} \mathrm{C}$.

\subsection{Result for acetone}

It is showed the plot of $\Delta \mathrm{T}$ versus $\ln (\mathrm{t})$ :

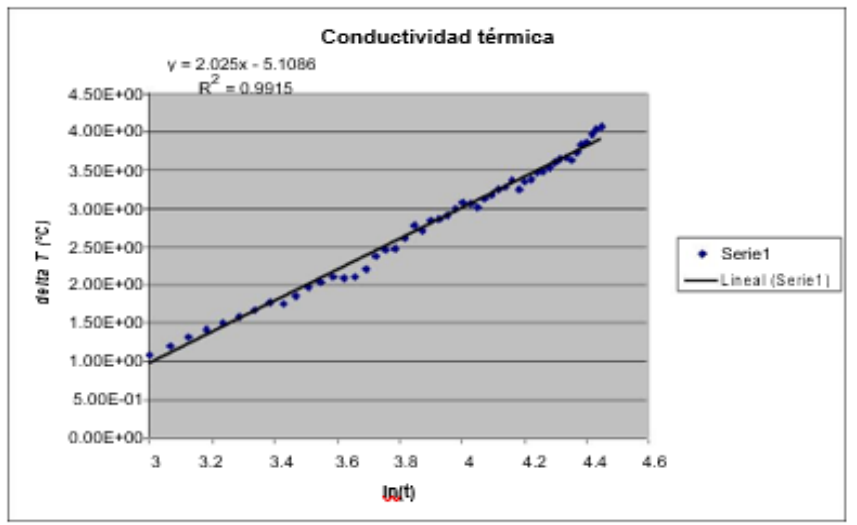

Fig.15 $\Delta \mathrm{T}$ versus $\ln (\mathrm{t})$ for Acetone (experiment)

The table of the thermal conductivity is presented:

\begin{tabular}{|l|r|l|l|l|}
\hline & & & \\
\hline$q^{q}=$ & $4.54 \mathrm{E}+00$ & $\mathrm{~W} / \mathrm{m}$ & Kreference $\left(\mathrm{W} / \mathrm{m}-{ }^{\circ} \mathrm{C}\right)=$ & 0.18 \\
\hline $\mathrm{m}=$ & $2.025{ }^{\circ} \mathrm{C}$ & & \\
\hline & & & $\mathrm{K}\left(\mathrm{W} / \mathrm{m}-{ }^{\circ} \mathrm{C}\right)=$ & 0.17869641 \\
\hline $\mathrm{K}\left(\mathrm{W} / \mathrm{m}-{ }^{\circ} \mathrm{C}\right)=$ & $\mathrm{q}^{\prime} /\left(4^{\star} 3.14^{\star} \mathrm{m}\right)$ & $\mathrm{E}=$ & $1.1 \%$ \\
\hline
\end{tabular}

Table 9: Calculations of the thermal conductivity for acetone (experiment) 
We can see that the error is less than $2 \%$ and the reference value of the thermal conductivity is

$\mathrm{k}=0.178 \mathrm{~W} / \mathrm{m}-{ }^{\circ} \mathrm{C}$.

\subsection{Summary table of results for water deionized, ethylene glycol and acetone}

The next table summarizes the values of the thermal conductivity for different liquids:

\begin{tabular}{|l|r|r|r|l|}
\hline & & & & \\
\hline & water deionized & ethylene glycol & acetone & \\
\hline K(measured) & 0.66 & 0.33 & $0.178\left(\mathrm{~W} / \mathrm{m}^{\circ} \mathrm{C}\right)$ \\
\hline K(reference) & 0.61 & 0.34 & $0.18\left(\mathrm{~m}-{ }^{\circ} \mathrm{C}\right)$ \\
\hline $\mathrm{E}$ & 8.19 & 2.94 & $1.11 \%$ \\
\hline
\end{tabular}

Table 10: Summary of the values of the thermal conductivity for different liquids (experiment)

In general, the error of the thermal conductivity are approximately lower than $8 \%$. Therefore, we got excellent results by simulation and experiment.

\section{Conclusions and Recommendations}

- The correction for the finite extension of the fluid and the correction for heat radiation loss are very small [7]. It is only necessary to consider the correction due to the coating. Nevertheless, we concluded that the coating only shifts the plot in the vertical axes without affects the slope.

- The experimental and reference values of the thermal conductivity are equals in the order of a decimal. The relative errors are lower than $8 \%$.

- The values of the thermal conductivity for acetone, water deionized and ethylene glycol at room temperature are analyzed and compared at the experimental part with good results.

- The value of the thermal conductivity for tungstate at $1000^{\circ} \mathrm{k}$ is obtained by numerical simulations and compared with the literature.

- It is necessary to use Pt-Rh $10 \%$ and high precision resistors to decrease the errors.

- It is also recommended to monitor the temperature with a thermocouple for example.

- At high temperature, it is better to use more thermocouples to monitor the uniformity of temperature of the fluid.

\section{Bibliography}

[1] Computerized, Transient Hot-Wire Thermal Conductivity (HWTC) Apparatus for Nanofluids; M. Kostic and Kalyan C. Simham; Department of Mechanical Engineering, Northern Illinois University, DeKalb, IL 60115, USA.

[2] Heareus Platinum Labware

[3] Simple apparatus for thermal conductivity measurements of unconsolidated powders; Abdelkader Outzourhit, John U. trejhy; Department of Physics, Colorado, USA.

[4] J. Physica, Chem Ref. Data 1972, 1, 279-421; Healy, J.J., de Groot, J.J.; Kestin.

[5] Int.J. Thermophysics; Nieto de Castro, C.A.; Li, S.F.Y.; Matiland, C.;Wakeham, W.; 1983, 4,311-327. 
[6] Thermal Conductivity of Electrically Conducting Liquids by the Transient Hot-Wire Method; Joseph G. Bleazard and Amyn S. Teja; J. Chem. Eng. Data 1995, 40, 732-737, Fluid Properties Research Institute, School of Chemical Engineering, Georgia Institute of Technology, Atlanta, Georgia 30332-0100.

[7] Experimental Set-Up for the Measurement of the Thermal Conductivity of Liquids; C. Codreanu, N.-I, Codreanu, V.V.N. Obreja; Romanian Journal of Information Science and Technology, Volume 10, Number 3, 2007,215-231; National Institute for Research and Development in Microtechnologies (IMT-Bucharest), Romania.

[8] Conduction of Heat in Solids, 2nd ed.; Carslaw, H.S.; Jaegar, J.C.; 2nd ed.; Oxford University Press; London, 1959.

[9] Radial-Axial Transient Heat Conduction in a Region Bounded Internally by a Circular Cylinder of Finite Length and Appreciate Heat Capacity; Kierkus, W.T., Mani, N., and Venart, J.E.S.; Canadian Journal of Physics, Vol.51, 1973, pp. 1182-86.

[10] The theory of the Transient Hot-Wire Method for Measuring Thermal Conductivity; Healy, J.J., de Groot, J.J., and Kestin, J.; Physica, Vol.82C, 1976, pp.392-408.

[11] Measuring Thermal Conductivity of Fluids Containing Oxide Nanoparticles; Argonne National Laboratory; S. Lee, S.U.-S. Choi, S. Li, J.A. Eastman; Vol. 121, May 1999.

[12] Measurement of thermal properties of electrically conducting fluids using coated transient hot wires; Richard A. Perkins; Thermophysics Division 838.02, National Institute of Standards, and Technology; Boulder, CO 80303, USA.

[13] Measurement of Thermal Conductivity and Thermal Diffusivity of Molten Carbonates; Hendro Wicaksono, Xing Zhang, Seiji Fujiwara, Motoo FujiII.

[14] Fundamentos de Transferencia de Calor; Frank P. Incropera, David P. Hewitt; Pearson Prentice Hall; 1986. 